\title{
Assessment of Salivary Zink Level and its impact on Periodontal Health among Children and Adolescence with Sickle Cell Anemia
}

Rogyia Eltayeb Hassan

Alneelain University

Lamis AbdelGadir Kaddam ( $\square$ lamiskaddam@hotmail.com )

King Abdulaziz University

\section{Research Article}

Keywords: Zinc, Saliva, Sickle, Periodontal Health

Posted Date: September 13th, 2021

DOI: https://doi.org/10.21203/rs.3.rs-821539/v1

License: (c) (i) This work is licensed under a Creative Commons Attribution 4.0 International License.

Read Full License 


\section{Abstract}

Background: Sickle cell anemia (SCA) is the most common inherited disorder around the world. It affects red blood cells resulting in severe hemolysis and painful crisis with multi-organ damage. Sickle cell anemia patients showed an impaired antioxidant status due to a reduced antioxidant defense mechanism that depends indirectly on zinc micronutrient. Several studies revealed a low level of serum zinc among sickle patients. However, none of them investigates the impact of SCA on salivary zinc level. This study aims to measure zinc level in saliva and its influence on the periodontal health of Sudanese children with SCA in Khartoum state. Up to our knowledge, this the first study conducted to measure salivary Zink level and its impact on periodontal health among sickle patients

Subjects and Methods: Cross-sectional study was conducted among children and adolescents aged 5-18 years old. Sixty individuals were involved, 30 with SCA compared to 30 healthy controls groups. An Atomic Absorption spectrophotometer quantified the salivary level of zinc. Periodontal examinations were assessed in SCA children using the periodontal community index.

Results: The mean ages in the sickle cell anemic group were $10.37 \pm 4.13$ years old, while the mean ages of subjects in the control group were $9.37 \pm 3.6$ years (P.Value: 0.169 ). Salivary zinc level was significantly lower among SCA patients (P.Value $<0.001$ ) than in the healthy control group. None of the participants were diagnosed with periodontitis. The less salivary zinc level was significantly higher in SCA with standard pocket depth and no clinical attachment loss than patients diagnosed with gingivitis ( $P$. Value:0.025).

Conclusions: Sickle patients have a low level of zinc in saliva, which may contribute to some manifestations of sickle cell disease and may make them more susceptible to periodontal disease in the future. We recommend conducting more research on oral and periodontal health among children affected with SCA to improve their quality of life.

\section{Background}

Sickle cell disease (SCD) is the most common hereditary hematological disorder throughout Africa, Middle East, and United States(1). SCD is characterized by chronic red blood cell hemolysis and vas occlusion associated with hypoxia(2). The pathophysiology of the disease is due to the polymerization of $\mathrm{HbS}$ in RBCs, leading to the occlusion of blood vessels(3). Children with SCD are at risk from severe morbidity that may impair their quality of life(1). Patients suffering from sickle cell anemia (SCA)had increased oxidative stress and peroxidation due to low antioxidants, leading to vaso-occlusive and painful crises (4-6). Impaired antioxidants status is due to reduced antioxidant defense mechanisms which, indirectly depend on zinc micronutrient (6-8). Zinc is an essential trace element for all forms of life, also crucial for the division of cells and the synthesis of DNA and proteins(8). Zink loss from biological membranes increases their susceptibility to oxidative damage and impairs their function (8). Significant effects of zinc deficiency include growth retardation, increased oxidative stress, and increased generation 
of inflammatory cytokines(6). Zinc has been considered an efficient antioxidant agent among humans (9, 10). Zink inhibits lipid peroxidation activity on red blood cells and protects against oxidative stress, and subsequently drops of incidence of vasocclusive and painful crisis(11-13). Researchers found that zinc deficiency is a common feature among SCA patients $(14,15)$. Zinc deficiency was connected to chronic hemolysis, increased demand and utilization, and secondary loss of zinc in urine $(16-18)(14,19)$. Certain clinical features are shared between SCA patients and zinc-deficient patients, like delayed puberty, short stature, and low body weight(20-23). The amount of zinc in plasma, erythrocyte, and hair was lower, and the urinary excretion of zinc is higher in SCA patients than in healthy control $(11,24,25)$. Zn deficiency can be diagnosed by both clinical features and laboratory findings(26-28)

Oral health is part of overall health and is an essential component of quality of life (29). Many systemic diseases affect oral and periodontal health (18). SCA is characterized by an impaired immune function that can affect oral health(30). Relation between salivary zinc and oral health revealed that zinc is essential for oral health maintenance (31-33). Earlier studies discovered that a low zinc diet profoundly impacts oral health and dental caries formation (34). Several studies discussed the association between gingival and periodontal health and SCA status without conclusive results (35-41). There were never published articles that determine the level of zinc in the saliva of patients that had sickle cell anemia. Advancements in treatment and medical care have allowed patients with SCA to have a better quality of life $(42,43)$. Therefore, it is essential to explore the impact of SCA on oral health and investigate possible underline mechanisms and pathogenesis.

The study investigates the salivary level of zinc and its relationship to the periodontal health of children and adolescents with SCA compared to healthy control groups.

\section{Methods}

\section{Study design and subjects}

A cross-sectional study was conducted at Khartoum state. The salivary samples were collected from thirty SCA cases regularly visiting refer clinics of Ibrahim Malik and Jafer ibn of Pediatric hospitals, and thirty matched healthy subjects visiting Khartoum dental teaching hospital without any periodontal disease.

\section{Inclusion and exclusion criteria}

The participants included in the study were aged 5-18 years old in both cases, and healthy control groups; known sickle cell anemic children regularly visit the refer clinic for follow-up. Patients with cardiovascular disease, epilepsy, and renal disorder and those with a history of antioxidant intake for the past three months were excluded.

\section{Data collection methods}


Clinical examination was evaluated with the inclusion criteria; they were informed about the study. After the parents agreed to participate, a questionnaire was obtained by the principal investigator asking about personal data and the history of the disease.

\section{Saliva collection}

Stimulated whole saliva $(2 \mathrm{ml})$ has been collected in the morning from participants between $9.00-11.00$ a.m. The subjects have been asked to rinse the mouth with distilled water thoroughly to remove any food debris. The participants allow the saliva to drool on the floor of the mouth until an adequate amount accumulate, then they were spitting off on a plain test tube. The procedure has been repeated until a sufficient amount is collected.

\section{Clinical oral examination and periodontal examination}

The plaque index with $\mathrm{PI}=0$ means good $\mathrm{OH}, \mathrm{PI} 1-2$ fair $\mathrm{OH}, \mathrm{PI}=3$ needy $\mathrm{OH}(23)$. The gingival index was scored;(GI= 0, no signs of gingival Inflammation, $\mathrm{GI}=1$ mean a sign of Inflammation without bleeding on probing, $\mathrm{Gl}=2$, gingival Inflammation provoked bleeding) $\mathrm{Gl}=3$ Spontaneous bleeding. Probing depth $(P D)$ has been measured in millimeters with a Williams periodontal probe by the principal investigator using infection control equipment.

\section{Saliva sample preparation for zinc estimation:}

Frozen saliva samples have been allowed to dissolve to room temperature before their analysis and subjected to biochemical preparation and centrifugation for 15 minutes at $4000 \mathrm{rpm}$ and diluted by $1 \%$ nitric acids 1:10(44). In salivary sample solution, the element is subjected to high thermal energy in order to produce the excited state atom performed by the flame of Atomic Absorption Spectrophotometry

Data were analyzed using SPSS version 23. Descriptive statistics (mean, standard deviation, minimum and maximum) were used in the present study. Inferential statistics (Student t-test, p-value and Spearman correlation) were also included. The significance level was accepted at $\mathrm{P} \leq 0.05$.

The Ethical Approval was obtained from Alneelain University IRB and from State Ministry of the health research department and approved the study protocol. Written informed consent was obtained from participants, legal guardians before enrollment.

\section{Results}

The mean ages of subjects in sickle cell anaemic group and control group were $10.37 \pm 4$.13years and $9.37 \pm 3.6$ years respectively. Sickle cell anemic group composed of $14(47 \%)$ Male and $16(53 \%)$ Female and the control group composed of 16 (53\%) Male, 14 (47\%) Female (table 1) The SCA patients had been diagnosed at an early age about 6 months. Regarding the past medical history, more than $80 \%$ of SCA patients develop an early signs and symptoms of upper and lower limbs swelling combined with severe 
pain . Concerning the management of the disease all SCA patient were using folic acid while 19 patients and five patients took in addition, hydroxyurea and omega three respectively .

More than $80 \%$ of the patient have never visit dental clinic before; only $16 \%$ of them had history of extraction and restorative treatment, $86.7 \%$ had fair oral hygiene (Table2).

There was significantly lower level of salivary zinc among sickle cell anemic patients as compared to healthy children the salivary zinc level with average of $0.5998 \pm 0.116 \mathrm{mg} / \mathrm{l}$ in control group and 0.18287 $\pm 0.103 \mathrm{mg} / \mathrm{l}$ in patients group (normal salivary level $(0.5-1.2 \mathrm{mg} / \mathrm{L})(1)$. Mean difference illustrate that the zinc level in control group is on average 0.417 greater than patient group $(p<0.0001)$ (Figure I). Medication showed no effect on saliva zinc level (Figure II). Zink level in SCA patients with gingival inflammation is on average 0.08 less than SCA with normal periodontal health (P. Value: 0.025) (Fig III).

\section{Discussion}

Sickle cell anemia is the most common hematological disease around the world (2). SCA is affecting whole body organ and oral cavity is not an exception $(3,4)$. Saliva contains many constituents that are regularly measured in the blood to monitor health and disease, so can be considered as a mirror of the body's health (5). While many researches investigate serum zinc' level (6-10); there is no reported study to assess salivary zinc level among SCA children. Best of our knowledge this study is first to assess salivary zinc level among SCA children and its impact on oral health.

In this study we find that SCA patients have significantly lower zinc level when compared to healthy participant (Figure 1). While researchers attributed lower serum zinc level to several factors including loss of zinc from red blood cells which is an important storage site for zinc(11). Furthermore, there is a defective zinc homeostasis as a result of excessive excretion(12). Low salivary zinc among SCA might be attributed to low serum level. Never the less prior studies showed that salivary and plasma zinc level are not correlated $(13,14)$. Oxidative stress which is cardinal sign of SCA pathogenesis may be the leading cause of zinc deficit in saliva. Since zinc is serve as cofactors of the metalloenzymatic superoxide dismutase(5). Interestingly neither hydroxyurea nor omega 3 influence salivary zinc level (Figure II). Hydroxyurea and Omega 3 served as anti-inflammatory agents among SCA patients $(15,16)$.

Many systemic diseases have effect on oral and periodontal health and SCA is not an exception $(3,4)$. Zinc in oral cavity is naturally present at various sites like dental plaque, dental hard tissue and saliva(17).It is proven to be effective against common prevalent oral health problems such as dental caries, gingivitis, periodontitis and malodour(17). Trace minerals like iron (Fe), zinc (Zn), selenium (Se) and copper $(\mathrm{Cu})$ are essential to inhibit progression of chronic conditions like periodontitis(18).Many systemic factors such as hormonal changes nutritional deficiency, compromised immune system could modified and affect periodontal tissue(18). In our study we find that there is a slight gingival inflammation in SCA groups aged more than 10 years old; since this age group is associated with 
morphological changes in gingiva due to eruption of permanent teeth(19). Our findings is in agreement with previous report's finding that SCA had no detected clinical periodontal disease or attachment loss, but GI (gingival index) was significantly higher in sickle patients (20). Brazilian researchers revealed that no clinical periodontal disease or attachment loss in was diagnosed among SCA patients(3). Though statistical analysis discovered that the zinc level in gingivitis group is on average 0.088 less than Normal group (Figure III). In animal experiments the mean plaque index and gingival index for were significantly lower in fed with a zinc-containing diet $(21,22)$. Both of these studies proposed zinc deficit as risk factor of oral and periodontal diseases. Zinc deficiency affects immune cells functions like monocytes natural killer cells, neutrophils, T cells and lymphocytes(18).

The limitation of the present study is the small sample size of the study population so there should be more studies on large population of SCA with various age groups to support our finding. In addition to raise awareness about the importance of oral health among SCA patients to improve quality of life.

\section{Conclusion}

The present study shows that SCA children and adolescents have lower zinc levels than healthy control groups, and the SCA patient revealed slight gingival inflammation with lower zinc level among adolescent groups.

\section{Declarations}

\section{Ethics approval and consent to participate:}

The Central Institutional Review Board at Al -Neelain University, approved the study. In addition, written informed consent was obtained from each participant's legal guardian prior to enrolment.

\section{Consent for publication:}

Principal investigator obtained informed consent from parents or guardian s to publish the data without breaching confidentiality.

\section{Availability of data and materials:}

The datasets used and/or analysed during the current study are available from the corresponding author on reasonable request.

\section{Competing interests:}

The authors declare that they have no competing interests

\section{Funding:}

Partial Fund was obtained from Alnnelain University to RH 
Acknowledgement:

The authors would like to thank the doctors of Pediatric hematology clinics and doctors in Khartoum Dental teaching hospital for their kind help. Dr. Omer Mohammed from Environmental and the Natural Resources Research Institute University of Khartoum for the kind help in sample analysis. Miss Sahar Almekashfi from the College of Mathematical Science and Statistics for assistance in data analysis.

\section{Author Contributions Statement:}

$\mathrm{RH}$, and LK participated in study design. $\mathrm{RH}$ and LK were involved in all aspects of the study conduct. $\mathrm{RH}$ collected data. RH and LK analysed data. RH\&LK participated in the writing and review of the manuscript. All authors have read and approved the manuscript

\section{Abbreviations}

SCA: Sickle Cell Anemia

Zn: Zink

GI : Gingival Index

\section{References}

1. Ogboko B. Trace element indices in hair and saliva of school children. J Basic Appl Sci Res. 2010;1(3):169-77.

2. Wastnedge E, Waters D, Patel S, Morrison K, Goh MY, Adeloye D, et al. The global burden of sickle cell disease in children under five years of age: a systematic review and meta-analysis. Journal of global health. 2018;8(2).

3. Brandão CF, Oliveira VMB, Santos ARRM, da Silva TMM, Vilella VQC, Simas GGPP, et al. Association between sickle cell disease and the oral health condition of children and adolescents. BMC oral health. 2018;18(1):1-9.

4. Singh J, Singh N, Kumar A, Kedia NB, Agarwal A. Dental and periodontal health status of Beta thalassemia major and sickle cell anemic patients: a comparative study. J Int Oral Health. 2013;5(5):53-8.

5. Hegde MN, Hegde ND, Ashok A, Shetty S. Biochemical Indicators of Dental Caries in Saliva: An in vivo Study. Caries Research. 2014;48(2):170-3.

6. Hasanato R. Alterations in serum levels of copper, zinc, and selenium among children with sickle cell anemia. Turkish journal of medical sciences. 2019;49(5):1287-91. 
7. Kudirat A, Kolade E, Ibrahim M. Serum zinc level during and after acute painful episodes in children with sickle cell anemia at the aminu kano teaching hospital, Kano, Northern Nigeria. Nigerian journal of clinical practice. 2019;22(1).

8. Prasad AS, Kaplan J, Brewer GJ, Dardenne M. Immunological effects of zinc deficiency in sickle cell anemia (SCA). Prog Clin Biol Res. 1989;319:629-47; discussion 48-9.

9. Temiye EO, Duke ES, Owolabi MA, Renner JK. Relationship between Painful Crisis and Serum Zinc Level in Children with Sickle Cell Anaemia. Anemia. 2011;2011:698586.

10. Onukwuli VO, Chinawa J, Eke CB, Nwokocha AR, Emodi IJ, Ikefuna AN. Impact of zinc on sexual maturation of female sickle cell anemia (SCA) children in Enugu, Southeast Nigeria. Pediatric Hematology and Oncology. 2018;35(2):145-55.

11. Simons TJB. Intracellular free zinc and zinc buffering in human red blood cells. The Journal of Membrane Biology. 1991;123(1):63-71.

12. Yuzbasiyan-Gurkan VA, Brewer GJ, Vander AJ, Guenther MJ, Prasad AS. Net renal tubular reabsorption of zinc in healthy man and impaired handling in sickle cell anemia. American Journal of Hematology. 1989;31(2):87-90.

13. Bales CW, Freeland-Graves JH, Askey S, Behmardi F, Pobocik RS, Fickel JJ, et al. Zinc, magnesium, copper, and protein concentrations in human saliva: age- and sex-related differences. The American Journal of Clinical Nutrition. 1990;51(3):462-9.

14. Greger JL, Sickles VS. Saliva zinc levels: potential indicators of zinc status. The American Journal of Clinical Nutrition. 1979;32(9):1859-66.

15. Yahouédéhou SCMA, da Guarda CC, Figueiredo CVB, Santiago RP, Carvalho SP, Fiuza LM, et al. Hydroxyurea alters hematological, biochemical and inflammatory biomarkers in Brazilian children with SCA: Investigating associations with $\beta S$ haplotype and a-thalassemia. PloS one. 2019;14(7):e0218040.

16. Daak AA, Lopez-Toledano MA, Heeney MM. Biochemical and therapeutic effects of Omega-3 fatty acids in sickle cell disease. Complementary Therapies in Medicine. 2020:102482.

17. Fatima T, Rahim Z, Lin CW, Qamar Z. Zinc: A precious trace element for oral health care. J Pak Med Assoc. 2016;66(8):1019-23.

18. Gaur S, Agnihotri R. Trace mineral micronutrients and chronic periodontitis-a review. Biological trace element research. 2017;176(2):225-38.

19. Bimstein E, Eidelman E. Morphological changes in the attached and keratinized gingiva and gingival sulcus in the mixed dentition period: A 5-year longitudinal study. Journal of clinical periodontology. 1988;15(3):175-9. 
20. Guzeldemir E, Toygar HU, Boga C, Cilasun U. Dental and periodontal health status of subjects with sickle cell disease. Journal of Dental Sciences. 2011;6(4):227-34.

21. Orbak R, Kara C, Ozbek E, Tezel A, Demir T. Effects of zinc deficiency on oral and periodontal diseases in rats. J Periodontal Res. 2007;42(2):138-43.

22. Seyedmajidi SA, Seyedmajidi M, Moghadamnia A, Khani Z, Zahedpasha S, Jenabian N, et al. Effect of zinc-deficient diet on oral tissues and periodontal indices in rats. International journal of molecular and cellular medicine. 2014;3(2):81.

\section{Tables}

Table 1: Background data of SCA and controls group:

\begin{tabular}{|c|c|c|c|c|}
\hline \multirow[b]{2}{*}{ Characteristics } & \multicolumn{3}{|l|}{ subjects } & \multirow[t]{2}{*}{$P$ value } \\
\hline & $\begin{array}{l}\text { Sickle patients } \\
(\mathrm{N}=30)\end{array}$ & $\begin{array}{l}\text { Control } \\
(\mathrm{N}=30)\end{array}$ & $\begin{array}{l}\text { Total } \\
(\mathrm{N}=60)\end{array}$ & \\
\hline Age in years (mean $\pm S D$ ) & $10.37 \pm 4.131$ & $9.37 \pm 3.662$ & & 0.169 \\
\hline Gender: Males & $14(47 \%)$ & $16(53 \%)$ & & 0.464 \\
\hline Females & $16(53 \%)$ & $14(47 \%)$ & & \\
\hline
\end{tabular}

$\mathrm{SD}=$ standard deviation, $\mathrm{p}$ value $>0.05$

Table 2: Dental history among sickle cell anemia group 


\begin{tabular}{|llll|}
\hline CHARACTERSTICS & & Frequency & Percent \% \\
\hline had you visit a dental clinic & No & 25 & 83.3 \\
\cline { 2 - 4 } & Yes & 5 & 16.7 \\
\cline { 2 - 4 } Type of dentition & Total & 30 & 100.0 \\
\cline { 2 - 4 } & Primary & 6 & 20.0 \\
\cline { 2 - 4 } & Mixed & 13 & 43.3 \\
\cline { 2 - 4 } & Permanent & 11 & 36.7 \\
\hline Periodontal health & Total & 30 & 100.0 \\
& Normal & 14 & 46.7 \\
\cline { 2 - 4 } & Gingival inflammation & 16 & 53.3 \\
\cline { 2 - 4 } & Total & 30 & 100.0 \\
\hline Oral hygiene status & Poor & 3 & 10.0 \\
\cline { 2 - 4 } & Fair & 26 & 86.7 \\
\cline { 2 - 4 } & Total & 29 & 96.7 \\
\hline
\end{tabular}

Figures 


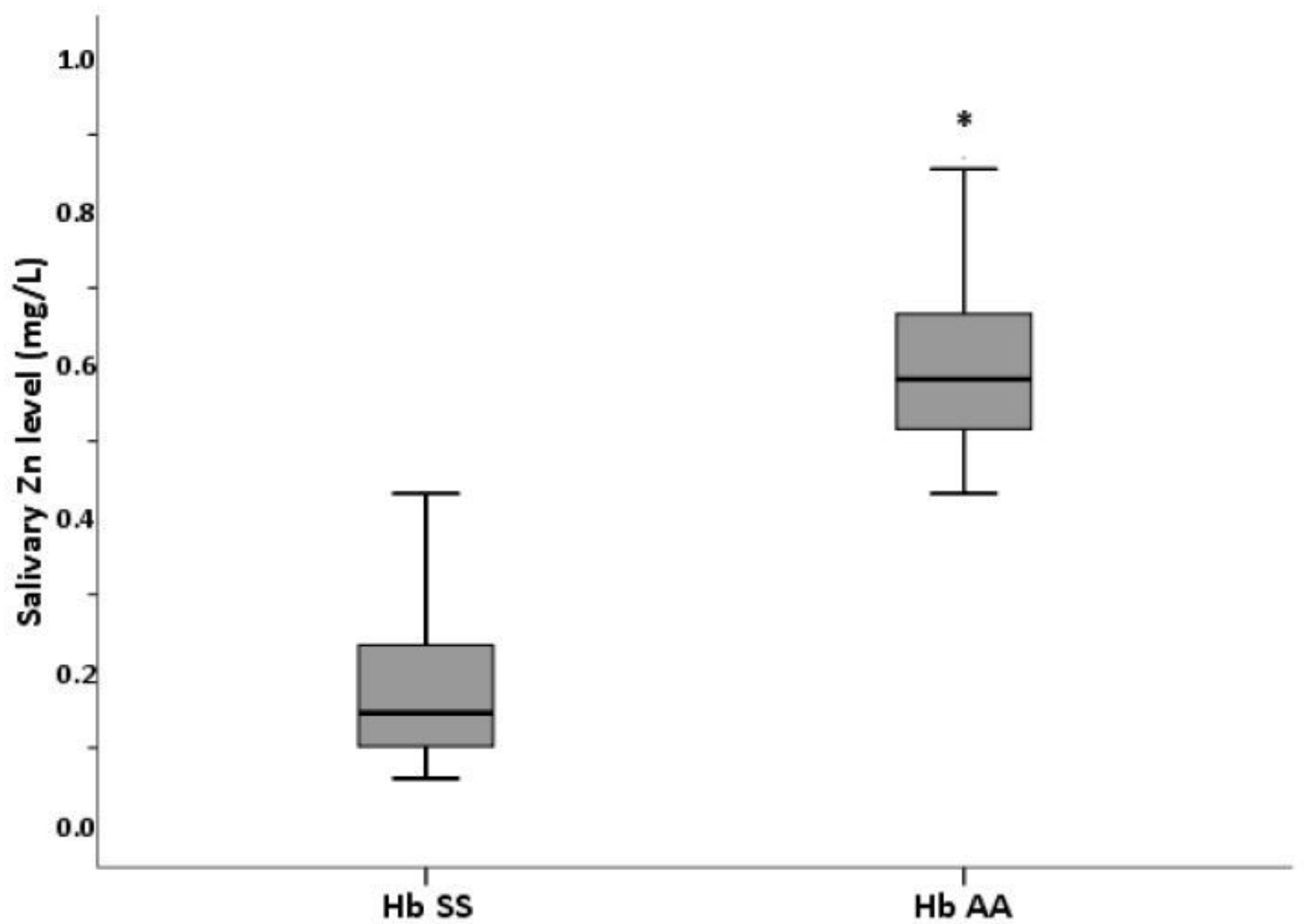

Figure 1

Salivary Zinc Level in Sickle Cell Disease Patients Compared to Control (P. Value $<0.001)$ * Indicates significant difference 


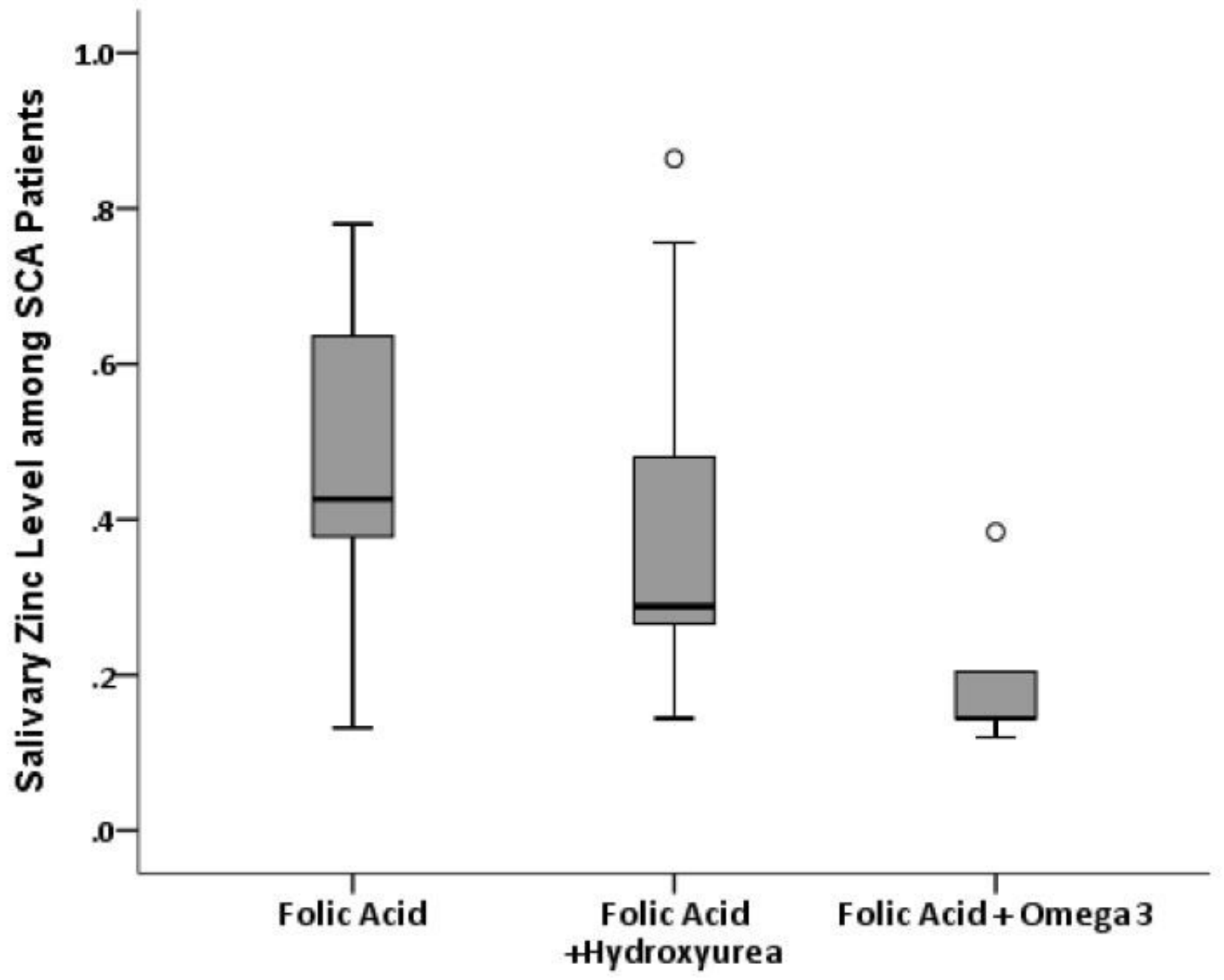

Figure 2

Salivary zinc level among SCA group sub divided by medication ( $P$. Value=0.266) 


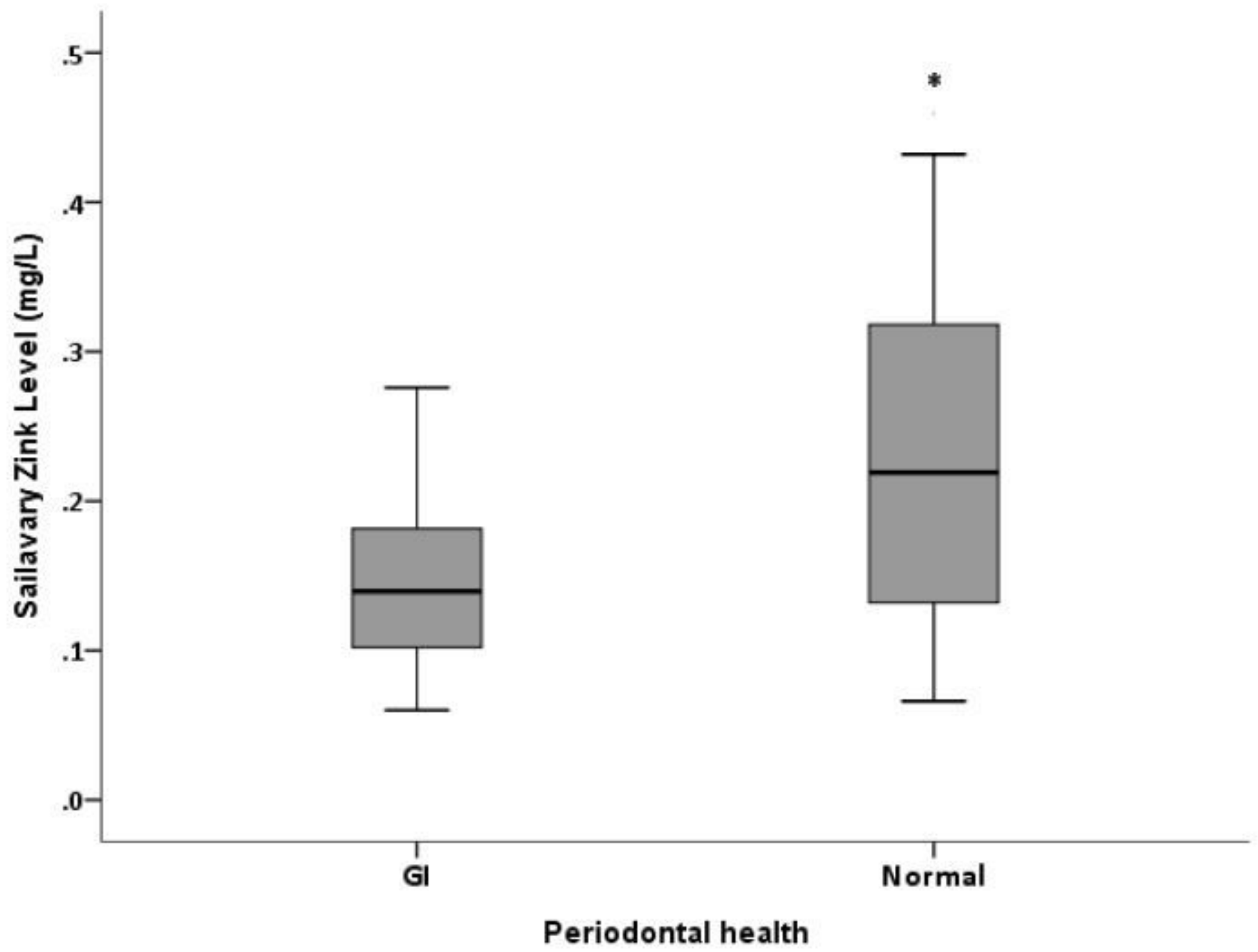

Figure 3

Salivary zinc level among SCA group sub divided by Periodontal health status ( $P$. Value=0.0.25) * Indicates significant difference 